\title{
Própolis: alternativa de tratamento como fitoterápico nas unidades básicas de saúde da família (UBSF)
}

A própolis é uma substância resinosa produzida pelas abelhas a partir de substâncias coletadas de diversas partes da planta como broto, botões florais e exsudatos resinosos. As atividades biológicas da própolis possibilitam o seu uso como alternativa de tratamento para as Infecções respiratórias Agudas (IRA). O objetivo desse trabalho foi avaliar a intenção de uso do extrato de própolis nas Unidades Básica de Saúde da Família (UBSF) quanto ao aspecto da aceitabilidade dos gestores e conhecimento/ prática da equipe e dos usuários da UBSF, para incorporar como tecnologia de fitoterápico no SUS. A pesquisa foi descritiva de abordagem quali-quantitativa, a abordagem qualitativa utilizou-se grupo focal com 06 gestores responsáveis pela atenção básica em Cáceres. A abordagem quantitativa realizou entrevistas com as categorias profissionais em quatro unidades UBSF de Cáceres e com mães de crianças e idosos, totalizando 160 participantes da UBSF, com a seguintes temas: conhecimento e a prática relacionada ao uso do extrato de própolis como fitoterápico; conhecimento sobre as plantas medicinais e intenção do uso da própolis no tratamento complementar das IRAs. Os gestores não apresentaram aceitabilidade ao uso da própolis como fitoterápico na rede de atenção básica como alternativa de tratamento. A intenção de uso da própolis como fitoterápico não foi diferente entre as categorias de profissionais da UBSF. Os idosos foram o que apresentaram a maior intenção de uso da própolis. O conhecimento e a prática de uso da própolis como fitoterápico não foram observados pelos participantes da UBSF. Como conclusão os gestores não apresentaram aceitabilidade ao uso da própolis e outros fitoterápicos na UBSF como alternativa de tratamento para IRA, mas se mostraram dispostos a discutir o uso da própolis nas UBSF se houver interesse por parte da comunidade em usar a própolis. As categorias profissionais que atuam nas UBSF, idosos, mães de crianças de 1 a 5 anos apresentaram conhecimento e prática restrito para o uso da própolis como tratamento de afeç̧ões respiratórias. Entretanto, os idosos e as mães de crianças apresentaram intenção de uso se a própolis for prescrita pelo médico e disponibilizada nas UBSF.

Palavras-chave: Fitoterápico; Unidade Básica de Saúde da Família; Política Nacional de Plantas Medicinais e Fitoterápicos.

\section{Propolis: alternative of treatment as phytoterapic in basic units of family health (UBSF)}

\begin{abstract}
Propolis is a resinous substance produced by bees from substances collected from various parts of the plant such as bud, flower buds and resinous exudates. The biological activities of propolis make it possible to use it as an alternative treatment for Acute Respiratory Infections (IRA). The objective of this study was to evaluate the intention to use the propolis extract in the Basic Units of Family Health (UBSF) regarding the aspect the acceptability of managers and knowledge / practice of the UBSF team and users, to incorporate as phytotherapeutic technology in the SUS. The research was descriptive of a qualitative-quantitative approach, the qualitative approach used a focus group with 06 managers responsible for basic care in Caceres. The quantitative approach carried out interviews with the professionals categories in four UBSF units of Caceres and with mothers of children and the elderly, totaling 160 participants of the UBSF, with the following topics: knowledge and practice related to the use of the propolis extract as a herbal remedy; knowledge about medicinal plants and the intention of using propolis in the complementary treatment of IRAs. The managers did not present acceptability to the use of propolis as an herbal remedy in the basic care network as an alternative treatment. The intention to use propolis as an herbal remedy was not different among the categories of professionals of the UBSF. In conclusion, the managers did not present acceptability to the use of the community. The professional's categories that work in the UBSF\, the elderly, mothers of children from 1 to 5 years presented restricted knowledge and practice for the use of propolis as a treatment of respiratory diseases. However, the elderly and the mothers of children presented intention to use if the propolis is prescribed by the physician and made available in the UBSF.
\end{abstract}

Keywords: Phytotherapic; Basic Family Health Unit; National Policy of Medicinal Plants and Phytotherapic

Topic: Epidemiologia e Saúde Ambiental

Reviewed anonymously in the process of blind peer.
Received: 02/02/2018

Approved: 20/05/2018

Eliana Cristina da Silva (D)

Universidade do Estado do Mato Grosso, Brasil http://lattes.cnpq.br/3617056131918146 http://orcid.org/0000-0001-7052-3067

eliana_cristinas@hotmail.com

\section{Carla Galbiati (iD)}

Universidade do Estado de Mato Grosso, Brasil http://lattes.cnpq.br/4449909695203792 http://orcid.org/0000-0001-5442-1562

\section{Referencing this:}

SILVA, E. C.; GALBIATI, C.. Própolis: alternativa de tratamento como fitoterápico nas unidades básicas de saúde da família (UBSF). Revista Ibero-Americana de Ciências Ambientais, v.9, n.1, p.73-87, 2018. DOI: http://doi.org/10.6008/CBPC2179-6858.2018.001.0006 


\section{INTRODUÇÃO}

A própolis é uma importante alternativa terapêutica, por possuir baixo custo e não causar resistência antibacteriana (ALMEIDA et al., 2016), ela possui inúmeras atividades biológicas e características que variam de acordo com o ambiente em que é produzida. A composição da própolis é um reflexo da flora utilizada pelas abelhas (MENDONÇA, 2011; COSTA et al., 2013). A própolis é uma substância resinosa produzida pelas abelhas a partir de substâncias coletadas de diversas partes da planta como broto, botões florais e exsudatos resinosos (PARK et al., 2002), enquadrada como opoterápico segundo a ANVISA (2005) e usada em tratamentos fitoterápicos (TAVARES et al., 2006). Ela apresenta várias substâncias, flavonóides é os grupos de compostos químicos que mais se destaca quanto à atividade biológica (SILVA et al., 2012).

As atividades que a própolis apresenta relacionadas as afecções do sistema respiratório são antiviral, imunológica e antibacteriana (SHIMIZU et al., 2008; SHIMIZU et al., 2011; MENEZES, 2005; FERNANDES JUNIOR et al., 2006). A própolis de vários locais do Brasil, inclusive de Cáceres/ Mato Grosso, tem comprovação contra a bactéria Staphylococcus aureus (LOUREIRO, 2008; BASTOS et al., 2011; BISPO JUNIOR et al., 2012, GOMES et al., 2016). Essa bactéria provoca afecção do sistema respiratório, essa afecção acomete crianças e idosos e é um problema de saúde pública (SALES et al., 2014; SANTOS et al., 2007).

As doenças respiratórias e otorrinolaringológicas podem ser tratadas com própolis como adjuvante em vacinas, isso devido ao aumento de resposta das células imunitárias e humorais como visto no estudo clínico (FISCHER et al., 2010). A própolis apresenta sinergismo com antibióticos comerciais em estudos in vitro (WOJTYCZKA et al., 2013).

As afecções do sistema respiratório são importantes causa de morbidade e mortalidade em menores de cinco anos, estão relacionadas à prescrição indiscriminada dos antibióticos (BENGUIGUI, 2003). A pneumonia é uma das principais complicações das afecções respiratórias, ocasionando impacto socioeconômico devido ao número de internações (BARROS et al., 2014).

A ampla utilização dos antibióticos pode causar a resistência bacteriana, o que leva a procurar formas alternativas de tratamento para diminuir essa resistência (OMS 2012). Uma forma alternativa de tratamento são os fitoterápicos, que podem ser utilizadas no combate a doenças entre elas as afecções do trato respiratório (SILVA et al., 2014).

Os fitoterápicos com indicação de uso, por meio de literatura científica indexada em bases de dados ou conhecimento popular, pode ser prescrito sem comprovação em estudo clínico (ANVISA, 2004).

A diretriz da Organização Mundial de Saúde (OMS) estimula a utilização dos fitoterápicos, por isso o Brasil aprovou em 2006 a Política Nacional das Práticas Integrativas e Complementares (PNPIC) e a Política Nacional de Plantas Medicinais e Fitoterápicas (PNPMF), para a inclusão da fitoterapia no SUS no âmbito da atenção básica (FIGUEREDO et al., 2014).

O uso dos fitoterápicos ajudas a suprir as demandas por medicamentos na atenção básica, além disso, terapias complementares como fitoterápicos poderá representar uma importante contribuição para o sistema (MARCHISIO et al., 2010). Entretanto, a capacitação da equipe multidisciplinar da UBSF é necessária, 
pois muitos médicos alegam não saber como prescrever os fitoterápicos (THIAGO et al., 2011). Além da carência de informações sobre o uso desse tipo de tratamento pelos profissionais de saúde 'LOPES et al., 2012).

Apesar do conhecimento sobre as plantas medicinais ser grande por parte da população, para a implantação viável de novas terapias no SUS, como fitoterápicos, deve atender aos sete pilares da qualidade em saúde que são: Eficácia, Efetividade, Eficiência, Otimização, Aceitabilidade, Legitimidade, Equidade (DONABEDIAN, 1994). A aceitabilidade depende de uma avaliação dos desejos dos pacientes e sua família no que se refere aos cuidados de saúde, e da sua avaliação do que seja efetivo e eficiente, bem como a relação existente entre o médico, paciente e tratamento (MALLET, 2005).

Os estudos de aceitabilidade devem ser realizados com os usuários e com os gestores, para demonstrar a eficácia e a viabilidade econômica dos fitoterápicos, e assim, fomentar a implantação do seu uso na atenção básica (FONTENELE et al., 2013) Esses estudos ajudam na inclusão de novas terapias no Brasil, assim como a construção de políticas com a fitoterapia nos municípios, estimulando a inserção de plantas medicinais e outros fitoterápicos no SUS (SILVA et al., 2014). A implantação do uso dos fitoterápicos no SUS foi detectada como dificuldade pelos gestores devido a ordem política e estrutural (FONTENELE et al., 2013). Isso mostra a importância conhecimento para a mudança de atitude e prática.

A aceitabilidade relacionada à saúde foi analisada sobre a intenção de uso de medicações, como quimioprofilaxia pelos portadores de hanseníase em Bangladesh (FEENSTRA et al., 2011) e a Quimio para prevenção da malária (TINE et al., 2013). A aceitabilidade do uso da quimioprofilaxia viabilizou a prevenção de hanseníase em regiões endêmicas (FEENSTRA et al., 2011).

Para se incorporar um novo produto ou uma nova alternativa tecnológica como medicamento é necessário verificar se é um bioproduto de ação comprovada(CÂNDIDO et al., 2013), e se atinge o objetivo no contexto de necessidade, eficiência e satisfação, por meio da interação do usuário com o produto/ tratamento (SILVA FILHO, 2011). O uso da própolis como fitoterápico na atenção básica vem ao encontro das diretrizes do SUS. Associado a boa aceitação na medicina popular da própolis devido as suas propriedades biológicas, o que ocasiona um crescente interesse pela sua utilização como produto natural para o controle das enfermidades (BEZERRA et al., 2013). A importância do conhecimento da fitoterapia é necessária para ampliar a atenção em saúde (SILVA et al., 2016), como proposto para a própolis.

A presente pesquisa teve como objetivo avaliar a intenção de uso do extrato de própolis nas Unidades Básica de Saúde da Família (UBSF) quanto ao aspecto da aceitabilidade dos gestores e conhecimento/ prática da equipe e dos usuários da UBSF, para incorporar como tecnologia de fitoterápico no SUS.

\section{METODOLOGIA}

\section{Abordagem Metodológica}


O estudo consistiu em pesquisa descritiva com o propósito de caracterizar o contexto das Unidades Básicas de Saúde da Família (UBSF) de Cáceres/MT, com abordagem quali-quantitativa.

A abordagem qualitativa foi utilizada para verificar a aceitabilidade dos gestores ao uso da própolis como uma prática de promoção a saúde, devido a eles serem os responsáveis pela adesão e implantação de políticas pública no município. A metodologia usada foi de grupo focal e seu detalhamento encontra-se no Quadro 1. O uso de grupo focal foi utilizado em outros estudos de aceitabilidade do uso de medicações (TINE et al 2013; FEENSTRA et al., 2011).

A abordagem quantitativa foi realizada para verificar o conhecimento e intenção de uso da própolis, bem como o uso de outros fitoterápicos pelas categorias profissionais que atua nas UBSF, e pelos usuários do SUS cadastrados nas UBSF. A metodologia usada foi entrevista com aplicação de questionários (Quadro 1). O uso de questionários na pesquisa sobre intenção de uso foi usado para avaliar um novo tipo de restauração por dentistas (CARLOTTO et al., 2014) e aceitabilidade dos métodos de vigilância no controle da dengue (SANTOS, 2014).

O local de estudo para abordagem quali-quantitativa foram as UBSF do município de Cáceres-Mato Grosso. As quatro UBSF selecionadas em Cáceres foram CAIC, Marajoara, Vila Real e Vitoria Regia, todas na zona urbana. A UBSF foi escolhida para a realização desta pesquisa devido à própolis ser usada no tratamento complementar da infecção Respiratória Aguda (IRA) e o atendimento inicial aos portadores de IRA acontecer na atenção básica.

Quadro 1. Caracterização da pesquisa descritiva quanto ao tipo de abordagem, participantes e coleta de dados.

\begin{tabular}{|c|c|c|c|c|}
\hline Abordagem & Metodologia & Participantes & $\begin{array}{c}\text { No de } \\
\text { participantes } \\
\text { (N) }\end{array}$ & Coleta de dados \\
\hline Qualitativa & Grupo focal & $\begin{array}{l}\text { Gestores públicos (coordenador } \\
\text { da Atenção Básica, coordenador } \\
\text { da Farmácia Municipal, } \\
\text { coordenador da Vigilância } \\
\text { Sanitária, membro do Conselho } \\
\text { Municipal de Saúde, } \\
\text { responsável pela Atenção } \\
\text { Básica junto ao Escritório } \\
\text { Regional de Saúde e o } \\
\text { Secretário Municipal de Saúde) }\end{array}$ & 06 & $\begin{array}{l}\text { Reunião com a discussão dos } \\
\text { temas: política Nacional de } \\
\text { Plantas Medicinais e } \\
\text { Fitoterápicos (PNPMF); adesão } \\
\text { do município à política; } \\
\text { elaboração de projeto de } \\
\text { utilização da própolis como } \\
\text { fitoterápico; recurso gastos e } \\
\text { necessários com atenção } \\
\text { básica }\end{array}$ \\
\hline \multirow[t]{2}{*}{ Quantitativa } & \multirow{2}{*}{$\begin{array}{l}\text { Entrevistas com os } \\
\text { participantes da Unidade } \\
\text { Básica da Saúde da } \\
\text { Família (UBSF). } \\
\text { Questionário com } 15 \\
\text { questões estruturadas e } \\
\text { semiestruturadas }\end{array}$} & $\begin{array}{l}\text { Categoria de profissionais } \\
\text { (médico, enfermeiro, técnico } \\
\text { em enfermagem e agente } \\
\text { comunitário de saúde) }\end{array}$ & 24 & \multirow[t]{2}{*}{$\begin{array}{l}\text { Temas abordados: } \\
\text { conhecimento e a prática } \\
\text { relacionada ao uso do extrato } \\
\text { de própolis como fitoterápico; } \\
\text { conhecimento sobre a PNPMF. }\end{array}$} \\
\hline & & $\begin{array}{l}\text { Usuários: } \\
\text { Idosos (>60 anos) } \\
\text { Mãe de crianças 1-5 anos }\end{array}$ & 136 & \\
\hline
\end{tabular}

O município de Cáceres está localizado a $210 \mathrm{~km}$ da capital Cuiabá possui uma população de aproximadamente 90.000 habitantes, $80 \%$ na área urbana e $20 \%$ na área rural. O município possui 19 Unidades Básicas de Saúde, das quais 11 são Unidades Básicas de Saúde da Família, 12 na zona urbana e 7 
na zona rural. A população do município coberta pela Estratégia da Saúde da Família (ESF) corresponde a 45\%, de acordo com Sistema de Informação de Atenção Básica (SIAB).

O número de usuários da USBF correspondeu a 10\% do número atendido em Cáceres em todas UBSF em 2014 e 2015. Os usuários foram sorteados de acordo com as fichas de atendimento da consulta médica no período de 2014 e 2015.

A presente pesquisa atendeu aos princípios previstos na resolução 466/2012 e Norma Operacional 001/2013 do Conselho Nacional de Saúde (CNS), aprovado pelo Comitê de Ética em Pesquisa/ UNEMAT sob o parecer CAAE 54119716.2.0000.5166.

\section{Análise dos dados}

As argumentações dos gestores durante o grupo focal foram classificadas por semelhanças e ordenadas em núcleos de sentido. Durante a análise final dos dados as etapas de ordenação e classificação foram necessárias para a compreensão e interpretação das falas, relacionando o conteúdo delas com a aceitabilidade de implantar um projeto de fitoterápicos com própolis e a adesão à PNPMF.

Para a caracterização dos participantes, dos usuários da UBSF foi analisado a idade, sexo, grau de escolaridade e renda foi por meio da distribuição da frequência em quartis.

Para verificar se “idosos, mães e as categorias profissionais das Unidades Básica de Saúde da Família apresentam conhecimento e prática sobre o uso do extrato de própolis" foi agrupado por frequência de produtos naturais usados como tratamento e os tipos de afecções tratadas com produtos naturais. As questões semiestruturadas foram agrupadas de acordo com as respostas e depois estimadas a média e a porcentagem usando o programa estatístico SPSS.

Para verificar a intenção de uso da própolis como fitoterápico foi aplicado teste de qui-quadrado $\left(X^{2}\right)$, em que o valor observado correspondeu ao número de respostas favoráveis à intenção de uso e o valor esperado foi $100 \%$ de intenção de uso para todas as questões (Equação 1). A hipótese nula do teste de quiquadrado foi que o conhecimento e a prática observados não diferem do esperado ao nível de $5 \%$ de probabilidade, o que significa que houve conhecimento e prática dos participantes ao uso do extrato de própolis ou dos fitoterápicos.

$$
X^{2}=\sum_{j-1}^{i} \frac{(A i j-E i j)^{2}}{E i j}
$$

Onde:

A=Número de respostas favoráveis a intenção de uso no SUS

$\mathrm{E}=$ Número total de questões intenção de uso no SUS

I= não inferior $\mathrm{a} 1$

$j=$ Total de pessoas entrevistadas (categorias profissionais= 24, usuários= 136)

Para verificar se a intenção de uso da própolis foi diferente entre o grupo de participantes da UBSF foi usada análise de variância, com significância $p=0,05$. A variável resposta foi a proporção intenção de uso 
da própolis, razão entre o número de respostas positivas para intenção de uso e o pelo número total de questões. A variável independente foi o grupo de participante com seis níveis (agente de saúde, enfermeira, idoso, mãe, médico e técnica de enfermagem). O teste de Tukey foi usado para comparação das médias entre o grupo de participantes sobre a intenção de uso.

As análises foram feitas nos programas Excel e R.

\section{RESULTADOS}

\section{Aceitabilidade do uso da própolis nas UBSF pelos gestores}

Para os gestores da saúde do município de Cáceres envolvidos com a atenção básica não houve aceitabilidade ao uso da própolis como tratamento complementar à IRA para idosos e crianças, bem como aceitabilidade ao uso dos fitoterápicos no município.

A implantação de um projeto de fitoterápicos com a própolis como tratamento complementar em casos de IRA não despertou o interesse dos gestores. Essa falta de interesse esteve relacionada ao desconhecimento e descrédito do uso da própolis associada a medicamentos convencionais. O uso da própolis como prevenção à IRA foi discutido com os gestores, mas não houve aceitabilidade devido a experiências negativas com programas implantados no município nas UBSF. Como exemplo foram citados a baixa adesão dos idosos à vacinação da gripe e das crianças à complementação da vitamina $A$.

A maioria dos gestores participantes do grupo focal afirmou que o uso da própolis como tratamento complementar dentro dos fitoterápicos é interessante, porém eles consideram que mais informações são necessárias para implantar um projeto com uso da própolis.

As informações solicitadas pelos gestores foram relacionadas ao desconhecimento sobre à contra partida necessária do município no projeto de fitoterápico junto ao Ministério da Saúde, dados relacionados ao uso da própolis em conjunto aos medicamentos convencionais e o número de casos de IRA entre os idosos e crianças de Cáceres. Eles consideram que o número de casos de IRA poderia ser uma justificativa para implantar o projeto.

Outras informações solicitadas pelos gestores foram a economia que o município poderia ter com o projeto de fitoterápicos, se haveria redução significativa no uso de medicamentos para IRA e exemplos de outros municípios que obtiveram sucesso na implantação do projeto de fitoterápico dentro do Estado.

Os gestores não aceitaram elaborar um projeto com uso da própolis mesmo após a argumentação de que a própolis local apresenta um baixo custo de produção, devido à existência do entreposto de mel pertencente a associação de produtores locais, a Associação de Apicultores do Alto Pantanal (APIALPA).

Para o uso da própolis na rede de atenção básica nas UBSF em Cáceres é necessário à adesão à Política Nacional de Plantas Medicinais e Fitoterápicos por parte do município. Os gestores foram informados sobre as vantagens dessa adesão para o município, mas esses não manifestaram positivamente sobre o assunto. Os gestores justificaram que a adesão do município de Cáceres deveria ser uma exigência do Governo Estadual, após a aprovação da lei estadual dos fitoterápicos em Mato Grosso. O projeto de lei está 
em estudo na Assembleia Legislativa do Estado, de autoria do Deputado Oscar Bezerra, sob o número: 2458/2015 Processo № 548/2015.

Outro ponto desfavorável à adesão dos gestores à Política de Fitoterápicos foi à época em que a reunião foi realizada, um mês antes das eleições municipais, próximo ao final do mandato do prefeito. Segundo os gestores a proximidade das eleições dificulta a aprovação de qualquer projeto encaminhado pelos gestores à Câmara Municipal de Vereadores. Além disso, alegaram que os vereadores apresentam morosidade em analisar os projetos encaminhados pela prefeitura, como o plano de saneamento básico de Cáceres, que há dois anos aguarda aprovação pela Câmara.

Com as discussões relacionadas aos recursos destinados à Atenção Básica e ao bloco farmacêutico verificou-se que eles não são suficientes para atender a demanda da população. Entretanto, os gestores não demonstraram interesse em aumentar a arrecadação de recursos junto ao Governo Federal com implantação de projeto de fitoterápico.

Em síntese, observou-se, por parte dos gestores que as dificuldades elencadas para adesão à política de fitoterápico, para a elaboração e a implantação de um projeto ao uso da própolis na rede de atenção básica das UBSF foram maiores do que o interesse.

\section{Conhecimento e prática do uso da própolis como fitoterápicos na rede das UBSF}

Em relação à idade dos usuários da UBSF os idosos concentraram na faixa etária de 73 a 94 anos e as mães de 17 a 40 anos (Tabela 1). A renda da maioria dos usuários foi de até 3 salários mínimos (72,1\%), os idosos são aposentados $(39,7 \%)$ e as mães do lar $(16,1 \%)$. A maioria dos idosos $(45,6 \%)$ possui apenas o ensino fundamental, seguido de analfabeto (23,5\%). Enquanto as mães 15,5\% possui nível médio e $11,75 \%$ ensino fundamental. A maioria dos usuários foi do sexo feminino devido às quarenta crianças sorteadas na pesquisa as mães foram às entrevistadas.

Tabela 1- Caracterização dos usuários das UBSF (idosos e mães) em Cáceres. (N=136 participantes).

\begin{tabular}{|c|c|c|c|c|c|}
\hline & \multirow[t]{2}{*}{ Classe } & \multicolumn{2}{|c|}{ Idosos } & \multicolumn{2}{|c|}{ Mães } \\
\hline & & $\mathrm{N}$ & $\%$ & $\mathrm{~N}$ & $\%$ \\
\hline \multirow{4}{*}{ Idade } & $17-40$ anos & - & - & 35 & 25,7 \\
\hline & 41-66 anos & 32 & 23,5 & 05 & 3,6 \\
\hline & $67-72$ anos & 30 & 22,1 & - & - \\
\hline & 73-94 anos & 34 & 25,1 & - & - \\
\hline \multirow[b]{3}{*}{ Renda familiar } & Nenhuma & 12 & 8,8 & 25 & 18,4 \\
\hline & Até 3 salários mínimos & 14 & 10,2 & 84 & 61,8 \\
\hline & Superior a 8 salários mínimos & 01 & 0,70 & - & - \\
\hline \multirow{4}{*}{ Escolaridade } & Analfabeto & 32 & 23,6 & - & - \\
\hline & Fundamental & 62 & 45,6 & 16 & 11,7 \\
\hline & Nível médio & 01 & 0,70 & 21 & 15,5 \\
\hline & Nível superior & - & - & 04 & 2,9 \\
\hline \multirow{2}{*}{ Sexo } & Feminino & 63 & 46,3 & 40 & 29,4 \\
\hline & Masculino & 33 & 24,3 & - & - \\
\hline
\end{tabular}

Os produtos fitoterápicos mais usados pelos idosos e mães foram as plantas medicinais, dos 128 produtos citados dois deles não foram plantas medicinais (mel e própolis) (Tabela 2). A própolis e o mel foram 
citados uma vez entre os entrevistados como fitoterápicos (1,7\%). A hortelã foi à planta mais usada, seguida do boldo, poejo, laranjeira, camomila e limão. Cinco plantas distintas tiveram frequência de 2,2 a 2,9\% de citações, 15 foram citadas de 1 a $2 \%$ e menor que $1 \%$ foram citadas 161 plantas (33,3\%). As plantas que foram citadas apenas uma vez foram 67 , representando $13,8 \%$ do total de produtos.

Em relação à prática de uso dos fitoterápicos as principais afecções foram respiratórias, gastrointestinais, geniturinárias e neurológicas, as demais tiveram 4,5\% ou menos (Tabela 3). A própolis e os fitoterápicos foram usados para tratamentos de várias afecções, a maioria do uso esteve relacionada mais aos fitoterápicos $(84,2 \%)$ do que à própolis. A própolis como tratamento foi utilizada para afecções respiratória $(10,6 \%)$ e imunológica $(1,5 \%)$, para outras 13 afecções foi citada apenas uma vez (3,5\%).

O conhecimento dos participantes da UBSF sobre a Política Nacional de Fitoterápico foi restrita a 30,5\% dos entrevistados e o interesse em incorporar a própolis como fitoterápico no SUS foi de 15,4\%. Apesar da baixa intenção de incorporar a própolis como tratamento complementar, a intenção de uso da própolis como tratamento complementar não diferiu entre a frequência observada e a esperada, com média 66,41\% $\pm 24,36(p=0,72 ; G L=159$, Figura 1). A intenção de uso de outros fitoterápicos pelos grupos de participantes da UBSF foi em média 76,81\% $\pm 20,47$, não diferindo do esperado ( $p=1,00 ; G L=159$, Figura 1).

Tabela 2- Produtos usados como fitoterápicos pelas mães e idosos nas UBSF em Cáceres-MT. N= número de citações feitas pelos entrevistados.

\begin{tabular}{|c|c|c|c|c|c|}
\hline Produto & $\mathbf{N}$ & $\%$ & Produto & $\mathbf{N}$ & $\%$ \\
\hline Hortelã & 42 & 8,7 & Romã & 9 & 1,9 \\
\hline Boldo & 37 & 7,7 & Alecrim & 8 & 1,7 \\
\hline Poejo & 23 & 4,8 & Babosa & 8 & 1,7 \\
\hline Laranjeira & 18 & 3,8 & Erva doce & 8 & 1,7 \\
\hline Camomila & 17 & 3,5 & Gengibre & 8 & 1,7 \\
\hline Limão & 17 & 3,5 & Mangueira & 8 & 1,7 \\
\hline Capim cidreira & 14 & 2,9 & Mel & 8 & 1,7 \\
\hline Terramicina & 12 & 2,5 & Arnica & 7 & 1,4 \\
\hline Algodão & 10 & 2,2 & Anador & 7 & 1,4 \\
\hline Caferana & 10 & 2,2 & Eucalipto & 7 & 1,4 \\
\hline Erva Santa Maria & 10 & 2,2 & Caninha do brejo & 6 & 1,2 \\
\hline Acerola & 9 & 1,9 & Amora & 5 & 1,0 \\
\hline Erva cidreira & 9 & 1,9 & Canela & 5 & 1,0 \\
\hline \multicolumn{4}{|c|}{ Outros produtos com menos de cinco citações } & 161 & 33,3 \\
\hline \multicolumn{4}{|l|}{ Total } & 483 & 100,0 \\
\hline
\end{tabular}

A intenção de uso da própolis como fitoterápico não foi diferente entre os grupos de participantes da UBSF ( $p=0,59, G L=154$ ), que variou de 62,75 a 78,28\%. A intenção de uso de outros fitoterápicos foi diferente entre os grupos de participantes $(p<0,0001, G L=154)$, os idosos foram o que apresentaram a maior intenção de uso $(82,08 \% \pm 3,72$, Figura 2$)$, seguido das mães, médicos e enfermeiros $(75 \% \pm 1,6)$, que não diferiram entre si. A menor intenção de uso dos fitoterápicos foi dos grupos de técnicos e agentes comunitários de saúde $(63,58 \% \pm 9,36)$.

O grupo de médicos foi composto por quatro médicos, três deles pertencentes ao Programa Mais Médicos oriundos de Cuba. Eles declararam ter conhecimento e prática com o uso de fitoterápicos, pois essa é uma prática comum na saúde pública daquele país. O único médico que não pertencia ao Programa Mais Médico apresentou conhecimento e prática do uso dos fitoterápicos, entre eles a própolis. Mesmo com 
apenas um médico brasileiro não houve diferença estatística quanto ao conhecimento e prática entre os médicos já que a frequência de resposta ficou entre 35 a $40 \%$ de conhecimento.

Tabela 3- Afecções tratadas com uso de própolis e outros fitoterápicos e a porcentagem em relação ao total de uso (\%) relatada pelas mães e idosos nas UBSF em Cáceres-MT. N=380 citações.

\begin{tabular}{ll}
\hline Afeç̧ões & Número de uso de fitoterápicos (\%) \\
\hline Respiratórias & $133(35,1)$ \\
Gastrointestinais & $79(20,7)$ \\
Geniturinárias & $30(7,8)$ \\
Neurológicas & $28(7,4)$ \\
Cardíacas & $17(4,5)$ \\
Tegumentar & $14(3,6)$ \\
Endócrinas & $11(2,8)$ \\
Imunológicas & $11(2,9)$ \\
Renal & $10(2,6)$ \\
Sanguíneas & $04(1,0)$ \\
Óssea & $02(0,6)$ \\
Outros usos & $41(10,9)$ \\
\hline Total & $380(100)$
\end{tabular}

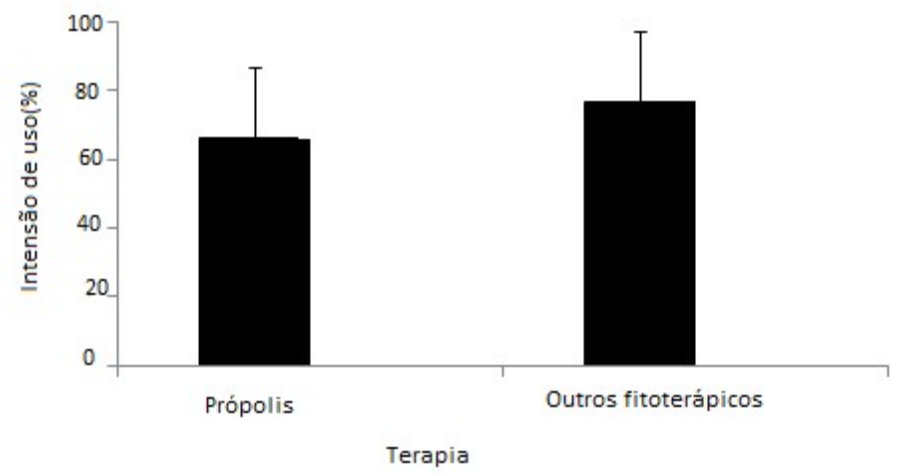

Figura 1- Intenção de uso de própolis como fitoterápico (\%) e de outros fitoterápicos pelos participantes das Unidades Básicas de Saúde da Família (UBSF) em Cáceres, MT. Dados representam a média \pm SD. Teste de qui-quadrado para própolis $p=0,72$, GL159; para fitoterápico $p=1,0, G L=159$.

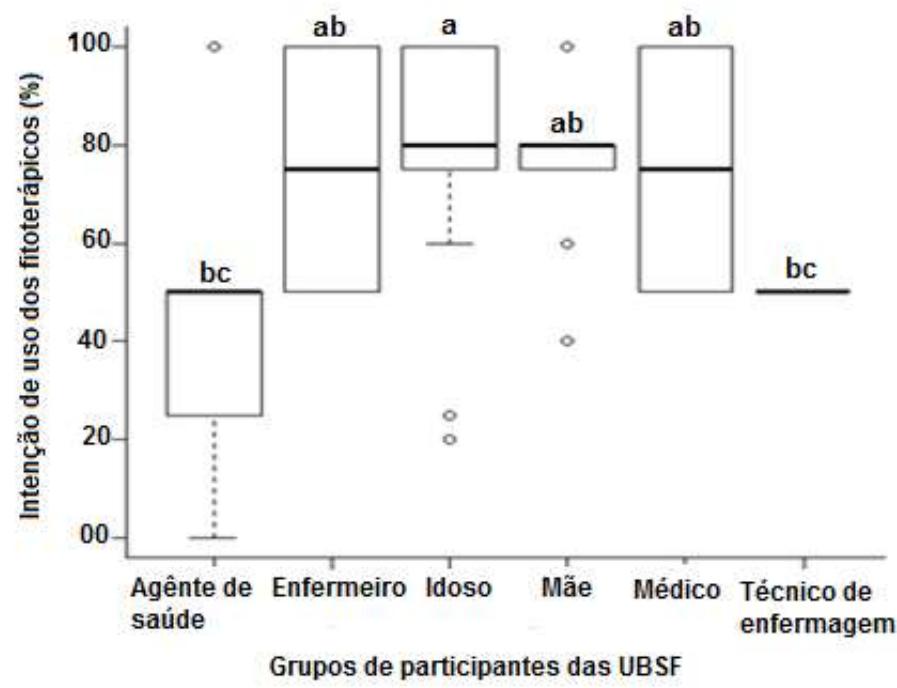

Figura 2- Intenção de uso dos fitoterápicos (\%) pelos diferentes grupos de participantes da Unidade Básica de Saúde da Família (UBSF) em Cáceres, MT. Dados representam a amplitude e a média. ANOVA p=0,0001, GL 154; média seguida das mesmas letras não diferiu estatisticamente pelo teste Tukey $(p<0,05)$. 


\section{DISCUSSÃO}

Os gestores não apresentaram aceitabilidade ao uso da própolis como fitoterápico na rede de atenção básica como forma de promoção a saúde, solicitaram informações relacionadas à eficiência do uso da própolis.

A falta do conhecimento por parte dos gestores da atividade da própolis e de sua eficácia em estudos clínicos pode justificar a não aceitabilidade na inclusão como tratamento complementar no SUS. Isso confirma a necessidade de se suprir a deficiência de tal conhecimento. O desconhecimento da eficácia de fitoterápicos devido à falta de informações foi um dos motivos de resistência da implantação de fitoterápico no SUS segundo Ibiapina et al. (2014). Essa resistência faz com que não seja possíveis ações práticas de promoções à saúde no município que é referência em atendimentos a saúde na região oeste do Mato grosso.

A sensibilização dos gestores para a aceitabilidade do uso da própolis poderia ser conseguida pela divulgação dos resultados sobre a atividade da própolis sobre os agentes causadores da IRA. A divulgação de estudos relacionados às atividades do extrato da própolis frente às bactérias (PORTILHO et al., 2013), bem como os estudos de eficácia em estudos clínicos como os realizados por Tavares et al.(2006) e Soares et al. (2006), poderiam vir a sensibilizar os gestores do município.

Quando os gestores alegaram interesse na implantação dos fitoterápicos na Atenção Básica na pesquisa de Fontenele et al. (2013), aproximadamente $20 \%$ deles apontam que a fitoterapia deve ser usada apenas para doenças leves. O que demonstra a necessidade da divulgação de estudos sobre a atividade da própolis e a eficácia e de outros fitoterápicos sobre a IRA, para que ocorra uma mudança de atitude por parte dos gestores da Atenção Básica.

Para que ocorra uma mudança de atitude relacionada a aceitabilidade dos gestores para uso própolis poderá ser elaborado um estudo futuro baseado na metodologia Conhecimento, Atitude e Prática (CAP), que é um método utilizado para medir o Conhecimento, Atitude e Práticas de uma comunidade (KALIYAPERUMAL, 2004). As ações de educação podem ser usadas para favorecer uma mudança de atitude em relação ao uso da própolis favorecendo a aceitabilidade dos gestores.

A parceria com as universidades é uma forma de ampliar o conhecimento sobre a efetividade da própolis como fitoterápico para as doenças do sistema respiratório. A inclusão de estudos relacionados aos fitoterápicos nos cursos de medicina aumentaram os índices de prescrição médica (SILVA et al., 2014; THIAGO et al., 2011). Como o uso dos fitoterápicos é baseado em estudos, essa inclusão poderia aumentar a demanda de uso dos fitoterápicos por parte da população atendida na Atenção Básica, pois eles usam os fitoterápicos prescritos.

A falta de conhecimento sobre o uso da própolis pelos usuários das UBSF pode ser devido ao produto não ser de fácil acesso em Cáceres, não estar disponível na farmácia da UBSF, e principalmente o custo no mercado não ser baixo. Os usuários do SUS têm preferência para os produtos mais baratos (FONTENELE et al., 2013). 
O produto de fácil acesso e baixo custo tem maior uso como visto nas pesquisas com plantas medicinais (FIGUEREDO et al., 2014; MARAVAl et al., 2011), muitas são de fácil cultivo e estão disponíveis em quintais domésticos, jardins e outros similares. Assim, para que ocorra o uso de produto fitoterápico é necessário que ele seja facilmente encontrado em estabelecimento comercial e de baixo custo (LOPES et al., 2014; THIAGO et al., 2011). Isso foi observado quanto ao uso de plantas medicinais como fitoterápicos. Os usuários preferem usar produto que apresente melhoria na qualidade de vida, seja de fácil acesso e, sem custo financeiro (SILVA et al., 2014).

O conhecimento sobre as plantas medicinais é transmitido através das gerações (FONTENELE et al., 2014), os idosos apresentam conhecimento sobre o boldo como planta medicinal, devido à facilidade de acesso e de informações sobre as plantas advindas de parentes. O conhecimento sobre plantas medicinais amplia a atenção em saúde (SILVA et al., 2016).

O baixo conhecimento e prática dos usuários do SUS sobre os fitoterápicos foi observado, porém constataram interesse e aceitação de uso (TAVARES et al., 2006). Isso indica um aspecto positivo na introdução de fitoterápicos na Atenção Básica, após capacitar os usuários quanto atividade da própolis frente a IRA, para aumentar o conhecimento e mudança de atitude, já que uma das características das redes de Atenção Básica é a de promoção a saúde com ações voltadas para a divulgação de novas terapias de conhecimento popular.

O desconhecimento sobre a política de fitoterápicos por parte dos enfermeiros foi um empecilho para a aceitabilidade dos gestores segundo Kauling et al. (2013). Os gestores elencaram como desafios a necessidade de estrutura física e capacitação profissional. Isso indica que os gestores percebem a necessidade de capacitação dos profissionais de saúde envolvidos no tratamento com fitoterápico para que o procedimento seja efetivo. A necessidade de capacitação dos profissionais para trabalhar com fitoterápicos foi verificada por Ibiapina et al. (2014), especificamente plantas medicinais, desde o cultivo até a prescrição.

A baixa intenção de uso dos fitoterápicos apresentada na presente pesquisa pelos técnicos de enfermagem e os agentes comunitários de saúde (63,58\%) pode ser relacionada ao desconhecimento sobre o uso racional das plantas medicinais e de outros fitoterápicos e a necessidade de capacitação relacionada ao tema através de ações em saúde. Isso foi confirmado em estudo sobre uso de medicamentos e fitoterápicos (KAULING et al., 2013).

As limitações da presente pesquisa foram relacionas ao período em que foi realizada a pesquisa qualitativa, próximo das eleições municipais e a troca das lideranças políticas poderia inviabilizar qualquer novo projeto. Outra limitação foi que a maioria dos médicos entrevistados fazia parte do Programa Mais Médicos, advindos de Cuba.

Avanços no uso do extrato de própolis nas Unidades Básicas de Saúde da Família (UBSF) como fitoterápicos, no tratamento da IRA, poderão ser conseguidos com um estudo sobre a eficácia semelhante. Esse estudo teria uma abordagem no uso efetivo e a vantagem econômica, associado à divulgação da atividade da própolis sobre a IRA para mudança de atitude e prática. 
Uma ação sobre conhecimento, atitude e prática (CAP) deve aumentar a informação sobre o uso da própolis pelos usuários da UBSF. O conhecimento baseado no uso favorece uma mudança de atitude em relação ao uso da própolis pelos usuários do SUS. A intervenção com ação de educação em saúde possibilitaria uma mudança de atitude como foi sobre o uso dos fitoterápicos e plantas medicinais por dentistas realizado por Carlotto et al. (2014), com mudança de atitude favorável.

O conhecimento e o uso de plantas medicinais como fitoterápicos podem estar condicionadas à orientação fornecida pelos profissionais da saúde e ao modo de uso (NAGAl et al., 2011). Assim, a prescrição da própolis pelos médicos poderá promover um incentivo ao seu uso, diminuindo o desconhecimento e mudando a atitude. Por outro lado, a indicação de uso dos fitoterápicos na Atenção Básica pelos médicos é variável, alguns são receptivos e aceitam (LOPES et al., 2012; MARAVAl et al., 2011) e outros alegam desconhecimento (SILVA et al., 2014), mas todos se mostram receptivos ao uso decorrente da crença em sua comprovação cientifica. Logo, estudo sobre o Conhecimento, Atitude e Prática (CAP) do uso da própolis poderia auxiliar os médicos.

A implantação de projeto futuro com uso de própolis na Atenção Básica poderá fomentar a apicultura localmente, com comercialização de mais um produto apícola além do mel. Com o aumento da produção de própolis será possível reduzir o custo e aumentar o consumo devido ao preço baixo. Como impacto socioeconômico disso a produção de própolis pode promover o desenvolvimento do Arranjo Produtivo Local em Apicultura localmente.

Promover debate com os gestores com ações em saúde sobre a eficiência da própolis poderá auxiliar na sensibilização para adesão ao seu uso em Cáceres. Associado ao debate deve ser divulgado resultado do conhecimento e a intenção dos usuários da UBSF (idosos e das mães) e dos médicos de Cáceres, em relação ao uso de fitoterápicos no SUS. Isso poderá contribuir para mudança de atitude, visto que a sensibilização de gestores foi alcançada pela divulgação da demanda de uso de plantas medicinais pela população (SILVA et al., 2014), que promoveu o uso dessa como fitoterápico no sistema público de saúde.

A indicação terapêutica da própolis como fitoterápico nas UBSF em Cáceres não está descartada devido à falta de aceitabilidade dos gestores, uma vez que a implantação de alternativa tecnológica envolve ainda pacientes, suas famílias e médico, com finalidade de alcançar a efetividade e aceitabilidade, uma vez que houve intenção de uso pelos usuários e médicos.

\section{CONCLUSÃO}

Os gestores não apresentaram aceitabilidade ao uso da própolis e outros fitoterápicos na UBSF como tratamento complementar para IRA, mas se mostraram dispostos a discutir o uso da própolis nas UBSF se forem disponibilizados novos trabalhos sobre o tema que comprovem as atividades biológicas da própolis e interesse por parte da comunidade em usar a própolis como tratamento complementar.

As categorias profissionais que atuam nas UBSF, idosos, mães de crianças de 1 a 5 anos apresentaram pouco conhecimento e prática do uso da própolis como tratamento de afecções respiratórias. Entretanto, os 
idosos e as mães de crianças apresentaram intenção de uso se a própolis for prescrita pelo médico e disponibilizada nas UBSF.

AGRADECIMENTOS: Os autores agradecem a FAPEMAT pela bolsa e o auxílio financeiro e a Secretaria de Saúde do Município de Cáceres.

\section{REFERÊNCIAS}

AGÊNCIA NACIONAL DE VIGILÂNCIA SANITÁRIA (ANVISA). Resolução - RDC no 132, de 29 de Maio de 2003. Dispõe sobre o registro de medicamentos fitoterápicos. D.O.U. Brasília, 2005.

AGÊNCIA NACIONAL DE VIGILÂNCIA SANITÁRIA (ANVISA). Resolução da Diretoria Colegiada RDC 48 de 16 de março de 2004. Diário Oficial da União de 18 de Março de 2004. Brasília.

ALMEIDA, D. C.; ALVES, D. C. B.; JARDIM JÚNIOR, I. J.; MENDONÇA, S. M. S.. Própolis na odontologia: uma abordagem de suas diversas aplicabilidades clínicas. Revista Fluminense de Odontologia. ano XXII, n. 46, Jul-Dez. 2016.

BARROS, M. M. A; MOURÃO, D.; HACON, S. S. Doenças respiratórias e internações em menores de 12 anos em um município da Amazônia ocidental. Revista Intertexto, v.1, p.1-15, 2014.

BASTOS, E. M. A. F. GALBIATI, C.; LOUREIRO, E. M.; SCOARIS, D. O.. Indicadores físico-químicos e atividade antibacteriana de própolis marrom frente à Escherichia coli. Arquivo Brasileiro Medicina Veterinária Zootecnia, v.63, n.5, p.12551259, 2011. DOI: http://doi.org/10.1590/S0102$\underline{09352011000500032}$

BENGUIGUI, Y. Controle das infecções respiratórias agudas no contexto da estratégia AIDPI nas Américas. Revista brasileira saúde materno infantil, v.3, n.1, p.25-36, 2003. DOI: http://doi.org/10.1590/S1519-38292003000100005

BEZERRA, K. K. S. BEZERRA, A. M. F.; SOUSA, L. C. F. S.; SOUSA, J. S.; SILVA, R. A.; BORGES, M. G. B. Atividade antimicrobiana da própolis em lesões cutâneas. Revista ACSA - Agropecuária Científica no Semi- Árido, v.9. n.1, p.17-23, 2013.

DOI: http://dx.doi.org/10.30969/acsa.v9i1.276

BISPO JUNIOR, W.; MIRANDA, E. O.; ALVINO, V.; ARAÚJO, B.; SILVA, D. W.; PORFIRIO, Z.. Atividade antimicrobiana de frações da própolis vermelha de Alagoas, Brasil. Semina: Ciências Biológicas e da Saúde, Londrina, v.33, n.1, p.3-10, 2012. DOI: http://doi.org/10.5433/1679$\underline{0367.2012 \mathrm{v} 33 \mathrm{n} 1 \mathrm{p} 03}$

CÂNDIDO, E. A. F.; FREITAS, M. M.; CÂNDIDO, J. F.; CERQUEIRA, F. L.. Nova alternativa tecnológica para medicamento direcionado à espasticidade. Revista IberoAmericana de Ciências Ambientais, Aquidabã, v.4, n.2, 2013. DOI: http://doi.org/10.6008/ESS21796858.2013 .002 .0008
CARLOTTO, C. A.; RAGGIO, D. P.; BONINI G. A. V. C.; IMPARATO J. C. P.. Aceitabilidade do tratamento restaurador atraumático pelos Cirurgiões-Dentistas do serviço público em São Paulo. Revista Associação Paulista de Cirurgiões Dentista, v.68, n.1, p.35-41, 2014.

COSTA, A. S.; MACHADO, B. A. S.; UMSZA-GUEZ2, M. A.; CIRQUEIRA, M. G.; NUNES, S. B.; PADILHA, F. F.. Levantamento dos estudos com a própolis produzida no estado da Bahia. Revista Sitientibus série Ciências Biológicas. n.13. p.1-7, 2013. DOI: http://doi.org/10.13102/scb324

DONABEDIAN, A.. Advantages and limitations of explicit criteria for assessing the quality of health care. Revista Health and Society, v.59, p.100-105, 1994.

FEENSTRA, S. G.; OSKAML, L.; NAHAR, Q.; RICHARDUS, J. H.. Acceptability of chemoprophylaxis for household contacts of leprosy patients in Bangladesh: a qualitative study. Leprosy Review Journal, v. 82, p. 178-187, 2011. DOI: http://doi.org/0305-7518/11/064053

FERNANDES JÚNIOR, A. LOPES, M. M. R.; COLOMBARI, V.; MONTEIRO, A. C. M.; VIEIRA, E. P.. Atividade antimicrobiana de própolis de Apis mellifera obtidas em três regiões do Brasil. Revista Ciência Rural, v.36, n.1, p.294-297, 2006. DOI: http://dx.doi.org/10.1590/S0103-84782006000100047

FIGUEREDO, C. A.; GURGEL, I. G. D.; GURGEL JUNIOR, G. D. A Política Nacional de Plantas Medicinais e Fitoterápicos: construção, perspectivas e desafios. Physis Revista de Saúde Coletiva, v.24, n.2, p.381-400, 2014. DOI: http://dx.doi.org/10.1590/S0103-73312014000200004

FISCHER, G.; PAULINO, N.; MARCUCCI, M. C.; SIEDLER, B. S.; MUNHOZ, L. S.; FINGER, P. F.; VARGAS, G. D.; HÜBNER, S. O.; VIDOR, T.; ROEHE, P. M.. Green propolis phenolic compounds act as vaccine adjuvants, improving humoral and cellular responses in mice inoculated with inactivated vacines. Revista Memorias do Instituto Oswaldo Cruz, v.105, n.7, p.908-913, 2010.

FONTENELE, R. P.; SOUSA, D. M. P.; CARVALHO, A. L. M.; OLIVEIRA, F. A.. Fitoterapia na Atenção Básica: olhares dos gestores e profissionais da Estratégia Saúde da Família de Teresina (PI), Brasil. Revista Ciência \& Saúde Coletiva, v.18, n.8, p.2385-2394, 2013. DOI:

http://dx.doi.org/10.1590/S1413-81232013000800023

GOMES, M. F. F.; ÍTAVO, C. C. B. F.; LEAL, C. R. B.; ÍTAVO, L. C. V.; LUNAS, R. C.. Atividade antibacteriana in vitro da própolis marrom. Revista Pesquisa Veterinária Brasileira. v.36, n.4, 
p.279-282, abr. 2016. DOI: http://doi.org/10.1590/S0100736X2016000400005

IBIAPINA, W. V.; LEITÃO, B. P.; BATISTA, M. M.; PINTO, D. S. Inserção da fitoterapia na atenção primária aos usuários do SUS. Revista Ciência Saúde Nova Esperança, v.12, n.1, p.5868, 2014.

KALIYAPERUMAL K. Guideline for conducting a knowledge, attitude and practice (KAP) study. Community Ophthalmology, n. 4, v.1, p. 7-9, 2004.

KAULING, G. P.; CERETTA, L. B.; SCHWALM, M. T.; DAGOSTIN, V. S.; SORATTO, M. T.. Utilização de medicamentos: limites e possibilidades das orientações dos Agentes Comunitários de Saúde às famílias. Revista o Mundo da Saúde, São Paulo. v.37, n.1, p.44-55, 2013.

LOPES, M. A.; OBICl, S.; ALBIERO, A. L. M. Interfaces Conhecimento e intenção de uso da fitoterapia em uma Unidade Básica de Saúde. Interfaces Científica-Saúde e Ambiente, v.01, n.01, p.53-59, 2012. DOI: http://dx.doi.org/10.17564/2316-3798.2012v1n1p53$\underline{59}$

LOUREIRO, E. M. Avaliação da própolis produzida em Cáceres-MT. Cáceres. Dissertação (Mestrado em Ciências Ambientais) - Universidade do Estado de Mato Grosso, Cáceres, 2008.

MALLET, A. L. R. Qualidade em Saúde: tópicos para discussão. Revista Brasileira de Cardiologia, v.18, n.5, 2005.

MARAVAI, S. G.; COSTA, C. S.; LEFCHAKO, F. J.; MARTINELLO, O. B.; BECKER, I. R. T.; ROSSATO, A. E.. Plantas medicinais: percepção, utilização e indicações terapêuticas de usuários da estratégia saúde da família do município de Criciúma- SC vinculados ao PET- Saúde. Revista Arquivos Catarinenses de Medicina, v.4, n.40, p.69-75, 2011. DOI: http://doi.org/0004$\underline{2773 / 11 / 40-04 / 69}$

MARCHISIO, P.; ESPOSITO, S.; BIANCHINI, S.; DESANTIS, C.; GALEONEI, C.; NAZZARI, E.; PIGNATARO, L.; PRINCIPI, N.. Effectiveness of a propolis and zinc solution in preventing acute otitis media in children with a history of recurrent acute otitis media. International Journal of Immunopathology and Pharmacology, v.23, n.2, p.567-575, 2010. DOI: http://doi.org/10.1177/039463201002300219

\section{MENDONÇA, L. S.. Aspectos ambientais, químicos e} biológicos relacionados à própolis vermelha Dissertação (Mestrado em Saúde e Ambiente) - Universidade Tiradentes, Aracaju, 2011.

MENEZES, H.. Própolis: uma revisão dos recentes estudos de suas propriedades farmacológicas. Revista Arquivos do Instituto Biológico, v.72, n.3, p.405-411, 2005.

NAGAI, S. C.; QUEIROZ, M. S.. Medicina complementar e alternativa na rede básica de serviços de saúde: uma aproximação qualitativa. Revista Ciência \& Saúde Coletiva, v.3, n.16, p.1793-1800, 2011. DOI: http://dx.doi.org/10.1590/S1413-81232011000300015

OMS. The evolving threat of antimicrobial resistence Options for action. Genebra: OMS, 125 p, 2012.
PARK, Y. K. et al. Própolis produzida no sul do Brasil, Argentina e Uruguai: evidências fitoquímicas de sua origem vegetal. Ciência Rural, v. 32, p. 997-1003, 2002.

PORTILHO, D. R.; MELO, I. A.; GUERRA, R. C.; BATISTA, H. L.; FERNANDES, C. H. C.. Avaliação da atividade antibacteriana e antifúngica da própolis produzida no estado do Tocantins. Revista Científica do ITPAC, Araguaína, v.6, n.2, Pb.1, 2013.

SALES, L. M.; SILVA, T. M. Staphylococcus aureus meticilina resistente: um desafio para a saúde pública. Acta Biomedica Brasiliensia, v. 3, n.1, p.1-13, 2012.

SANTOS, K. C.; SIQUEIRA JÚNIOR, J. B.; ZARA, A. L.S.A.; BARBOSA, J. R, OLIVEIRA, E. S. F.. Avaliação dos atributos de aceitabilidade e estabilidade do sistema de vigilância da dengue no estado de Goiás, 2011, Revista Epidemiologia Serviços de Saúde, Brasília, v.23, n.2, p.249-258, 2014. DOI: http://doi.org/10.5123/S1679-49742014000200006

SHIMIZU, T.; HINO, A.; TSUTSUMI, A.; PARK, Y. K.; WATANABE, W.; KUROKAWA, M.. Anti-influenza virus activity of propolis in vitro and its efficacy against influenza infection in mice. Antiviral Chemistry \& Chemotherapy, v.19, p.7-13, 2008. DOI: http://doi.org/10.1177/095632020801900102

SILVA FILHO A. M.. Usabilidade e user experience: essencial para aceitabilidade de produtos e serviços. Revista Espaço Acadêmico, n.124, p.43-51, 2011.

SILVA, J. C.; RODRIGUES, S.; FEÁS, X.; ESTEVINHO, L. M.. Antimicrobial activity, phenolic profile and role in the inflammation of propolis. Food and Chemical Toxicology, v.50, p.1790-1795, 2012. DOI: http://doi.org/10.1016/i.fct.2012.02.097

SILVA, L. A. D.; ALBIERO, A. L. M. Programas de fitoterapia na atenção primária à saúde: existem experiências exitosas? Revista Brasileira de Farmácia, v. 3, n. 95, p. 889 - 908, 2014.

SOARES, A. K. A; CARMO, G. C.; QUENTAL, D. P; NASCIMENTO, D. F.; BEZERRA F. A. F.; MORAES M. O.; MORAES M. E. A.. Avaliação da segurança clínica de um fitoterápico contendo Mikania glomerata, Grindelia robusta, Copaifera offi cinalis, Myroxylon toluifera, Nasturtium offi cinale, própolis e mel em voluntários saudáveis. Revista Brasileira Farmacognosia, v.4, n.16, p.447-454. 2006. DOI: http://dx.doi.org/10.1590/S0102-695X2006000400002

SANTOS, A. L.; SANTOS, D. O.; FREITAS, C. C.; FERREIRA, B. L. A.; AFONSO, I. F.; RODRIGUES, C R.; CASTRO, H. C..

Staphylococcus aureus: visitando uma cepa de importância hospitalar. Journal Brasileiro Patologia Medicina Laboratorial, v.43, n.6, p.413-423, 2007.

TAVARES, J. P.; MARTINS, I. L.; VIEIRA, A. S.; LIMA, F. A.; BEZERRA, F. A. F.; MORAES, M. O.. Estudo de toxicologia clínica de um fitoterápico a base de associações de plantas, mel e própolis. Revista Brasileira Farmacognosia, v.3, n.16, p.350-356. 2006. DOI: http://dx.doi.org/10.1590/S0102$\underline{695 \times 2006000300012}$

THIAGO, S. C. S; TESSER, C. D. Percepção de médicos e enfermeiros da Estratégia de Saúde da Família sobre terapias complementares. Revista Saúde Pública, v.45, n.2, 
p.249-57, 2011. DOI: http://dx.doi.org/10.1590/S003489102011005000002

TINE, R. C. K.; DIAYE, P. N.; DOUR C. T. N.; FAYE, B.; NDIAYE, J. L.; SYLLA, K.; DIAYE, M. N.; CISSE, B.; SOW, D.;

MAGNUSSEN, P.; BYGBJERG, I. C.; GAYE, O.. Acceptability by community health workers in Senegal of combining community case management of malaria and seasonal malaria chemoprevention. Malaria Journal. v.467, n.12, 2013. DOI: https://doi.org/10.1186/1475-2875-12-467
WOJTYCZKA, R. D.; DZIEDZIC, A.; IDZIK, D.; KĘPA, M.; KUBINA, R.; KABAŁA-DZIK, A.; SMOLEŃ-DZIRBA, J.; STOJKO, J.; SAJEWICZ, M.; WĄSIK, T. J.. Susceptibility of Staphylococcus aureus Clinical Isolates to Propolis Extract Alone or in Combination with Antimicrobial Drugs.

Molecules, v.18, p.9623-9640, 2013. DOI:

http://doi.org/10.3390/molecules18089623

A CBPC - Companhia Brasileira de Produção Científica (CNPJ: 11.221.422/0001-03) detém os direitos materiais desta publicação. Os direitos referem-se à publicação do trabalho em qualquer parte do mundo, incluindo os direitos às renovações, expansões e disseminações da contribuição, bem como outros direitos subsidiários. Todos os trabalhos publicados eletronicamente poderão posteriormente ser publicados em coletâneas impressas sob coordenação da Sustenere Publishing, da Companhia Brasileira de Produção Científica e seus parceiros autorizados. Os (as) autores (as) preservam os direitos autorais, mas não têm permissão para a publicação da contribuição em outro meio, impresso ou digital, em português ou em tradução. 